\title{
THE PREVALENCE OF DRUG-DRUG INTERACTIONS OF PRESCRIPTIONS DISPENSED IN COMMUNITY PHARMACIES IN NAJAF CITY-IRAQ
}

\author{
SAMER NOORI HASHIM ${ }^{1}$, MOHAMMED JAWAD SALIH AL-HAIDAREY ${ }^{2 *}$ \\ ${ }^{1}$ Department of Clinical Pharmacy, University of Kufa, Kufa, Iraq. ${ }^{2}$ Department of Ecology, University of Kufa, Kufa, Iraq. \\ Email: mohammedj.alhayderi@uokufa.edu.iq
}

Received: 8 March 2019, Revised and Accepted: 22 July 2019

\section{ABSTRACT}

Objectives: The main objectives of this work were to estimate the frequency, type, and nature of possible drug-drug interactions in prescriptions dispensed from community pharmacies in Al-Najaf city, secondary objectives were the study of the association between specialty of physicians and the rate of recurrence of drug-drug interactions and to determine medication classes, which were involved in possible drug-drug interactions.

Methods: To investigate this study, 211 prescriptions dispensed in three community pharmacies in Al-Najaf city were collected and by the computerized screening program to identify drug-drug interactions.

Results: The results showed that the total number of interactions was recognized to be $41 \%$ of all prescriptions with the prevalence of major drugdrug interactions was $14 \%$, minor was $16 \%$, and moderate was $70 \%$.

Conclusions: This study concluded that most identified drug-drug interactions were recognized in prescriptions written by an internal medicine specialist, orthopedics, general practitioners, an ear-nose-throat specialist, and general surgeon. The ratio of drug-drug interactions/number of prescriptions increased with increasing the number of drugs prescribed per patient $(r=0.93$, regression $p<0.05)$. This study suggested that the role of the pharmacist should be moved from medication-oriented to patient-oriented, and the clinical pharmacists should have a vital function in recognizing and avoiding drug-drug interactions in prescriptions dispensed to patients.

Keywords: Drug-drug interactions, Community pharmacy, Prescriptions.

(C) 2019 The Authors. Published by Innovare Academic Sciences Pvt Ltd. This is an open access article under the CC BY license (http://creativecommons. org/licenses/by/4. 0/) DOI: http://dx.doi.org/10.22159/ajpcr.2019.v12i9.32960

\section{INTRODUCTION}

Drug-drug interactions lead to a change of the action of one or more simultaneously administered drugs and that interactions classified as pharmacodynamic or pharmacokinetic, and may affect the effectiveness of medication [1]. Many drug-drug interactions, there was only a small part "clinically" significant [2]. Polypharmacy has been related to the occurrence of drug-drug interactions, medication errors, and adverse drug reactions $[3,4]$. Several researches recommend that drug-drug interactions may be the reason of about $3 \%$ of all hospital admittances [5]. Clinical pharmacists play an important role in protecting the patients from the hazards of potential drug-drug interactions, mainly with medications with a narrow therapeutic index $[6,7]$.

Manual evaluation of drugs in a prescription can be completed by clinical pharmacists, but the efficacy in the finding of drug-drug interactions is about $50 \%$ in a two-drug prescription, and the percentage decreases significantly as the number of drugs increases [8]. Using the electronic drug-drug interactions screening databases, we can considerably increase the finding of the potential dangers of that interaction, beyond what can be completed with manual evaluation alone [9].

The aims of this work were to estimate the frequency, type, and nature of possible drug-drug interactions in prescriptions dispensed from community pharmacies in Al-Najaf city, secondary objectives were the studies of the association between specialty of physicians and the rate of recurrence of drug-drug interactions and to determine medication classes, which were involved in possible drug-drug interactions.

\section{METHODS}

Three-community pharmacy was selected randomly in Al-Najaf city to obtain a prescription from different physician specialty. All 1015 dispensed medications in 211 prescriptions were collected during a 5 months. The data that we collected from the prescriptions were included: Age, gender, date of the prescription, diagnosis (if present), specialty of the prescribing physicians, name of the medications in each prescription, dosage, and quantity of medications dispensed. The possibility of drug-drug interactions was identified using the drug interactions checker [10]. Furthermore, the identified drug-drug interactions were categorized as major and moderate, depending on the severity of clinical importance.

For statistical analysis, IBM-SPSS statistics 24 was used. Pearson's correlation coefficient considered to test the correlation (effects were considering statistical significant as $\mathrm{p}<0.05$ ).

\section{RESULTS}

A total of (1015) drugs were prescribed to 211 prescriptions dispensed (Table 1). The average number of medications per patient was found to be $4.5 \pm 2.29$ (range=1-8). Of the 211 prescriptions one had only one drug and the remaining (210) prescriptions had two or more drugs. Prescriptions with two or more drugs were checked for identified drug-drug interactions electronically using the drug interactions checker within www.drugs.com and classified as major and moderate according to their level of clinical importance.

The total number of interactions was recognized to be 86 of all prescriptions. Of these 86 drug-drug interactions, 12 were majors, 60 were moderates, and 14 were minor (Fig. 1). Of the 12 major drug-drug interactions, seven cases involved pharmacokinetic interaction and five cases involved pharmacodynamics interaction. Major drug-drug interactions were recognized in prescriptions of patients with chronic illnesses. The most common diagnosis was found to be specialty 
Table 1: Describe the data collected during this study

\begin{tabular}{lllllllll}
\hline Gender & \multicolumn{1}{l}{ Male } & & & & & & \\
\hline \#of drug/ & 1 & 2 & 3 & 4 & 5 & 6 & 7 & 8 \\
prescription & & & & & & & & \\
$\quad$ Interaction & 0 & 1 & 5 & 5 & 8 & 6 & 10 & 8 \\
$\quad$ \#of prescription & 1 & 10 & 16 & 20 & 17 & 13 & 11 & 9 \\
Sum & 1 & 20 & 48 & 80 & 85 & 78 & 77 & 72 \\
Age (mean \pm SD) & $54.3 \pm 6.2$ & & & & & & \\
\hline Gender & Female & & & & & & \\
\hline Interaction & 0 & 2 & 4 & 7 & 5 & 9 & 7 & 9 \\
$\quad$ \#of prescription & 0 & 12 & 17 & 24 & 20 & 16 & 13 & 12 \\
Sum & 0 & 24 & 51 & 96 & 100 & 96 & 91 & 96 \\
$\quad$ Age (mean \pm SD) & $48.6 \pm 8$ & & & & & & \\
Total drugs of & 1 & 44 & 99 & 176 & 185 & 174 & 168 & 168 \\
male and female & & & & & & & \\
\hline
\end{tabular}

SD: Standard deviation

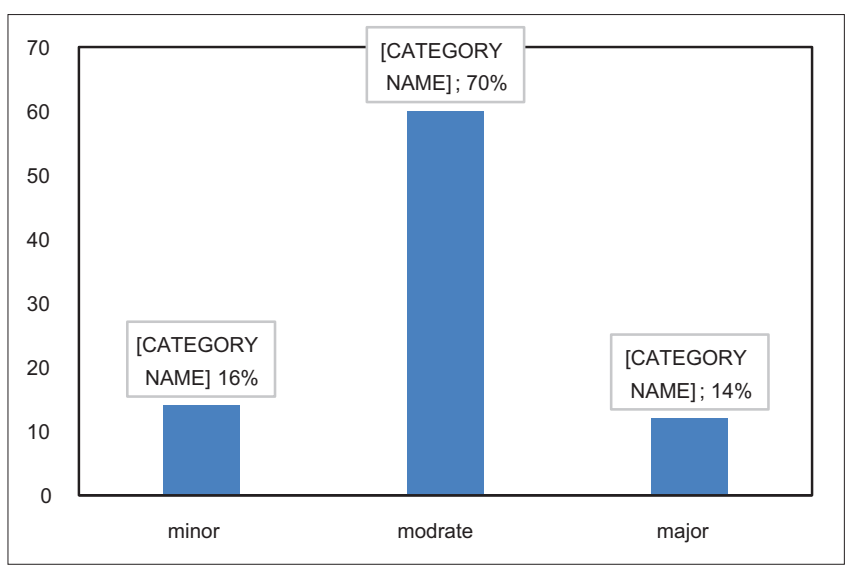

Fig. 1: The percentage of minor, moderate, and major of drug-drug interaction

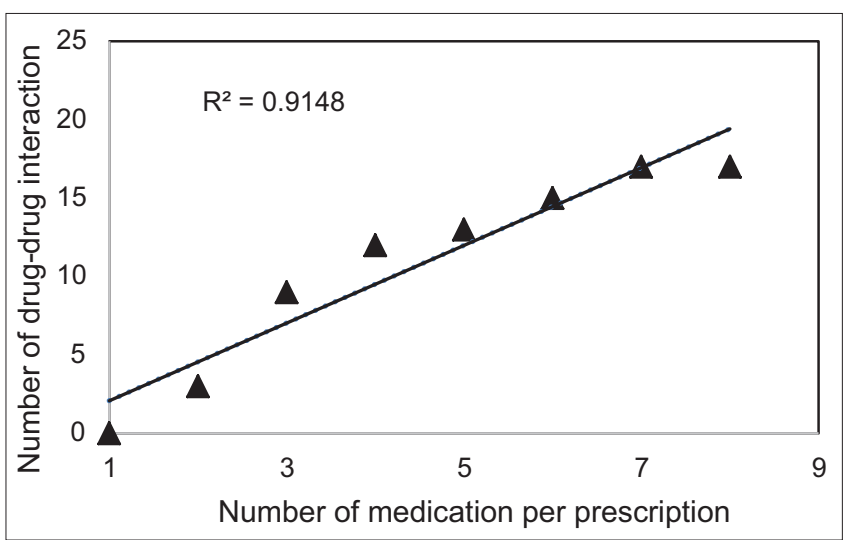

Fig. 2: The Pearson's correlation coefficient between the number of medication per prescription and number of drug-drug interaction

chronic respiratory disease (3) and coronary heart disease (6) and one was rheumatoid arthritis.

The greater ratio of moderate and minor was founded in orthopedics $(25 \%)$, general practitioners $(16,67 \%)$, ear-nose-throat (ENT) specialist (8.34\%), and general surgeon (8.34). As show in Fig. 2 the ratio of drug-drug interactions/number of prescriptions increased with increasing the number of drugs prescribed per patient. Finally, the ratio of drug-drug interactions per the number of prescriptions increased significantly with increase the number of drugs prescribed per patient $(\mathrm{r}=0.93$, regression $\mathrm{p}<0.05)$.

\section{DISCUSSION}

The current research showed that the overall frequency of identified drug-drug interactions in prescriptions dispensed in community pharmacies in Al-Najaf city was $40.95 \%$. The potential drug-drug interactions were classified depending on their severity, as major (dangerous interaction and need medical interferences to decrease or avoid severe toxic effects) and moderate (the interaction may increase the patient's illness and/or need a change in medications). The prevalence of the major drug-drug interactions was $5.71 \%$ of all prescriptions dispensed, while the prevalence of the moderate drug-drug interactions was $35.24 \%$ of all prescriptions dispensed.

When comparing the prevalence of the major drug-drug interactions in the current study to the prevalence of the major drug-drug interactions in other studies which done in Greece [11] and Iran [12], we found that they recognized that $13.7 \%$ and $10.8 \%$ had major potential major drugdrug interactions respectively.

The prevalence of the major drug-drug interactions increases in the elderly (at least 60 years old) as identified by Brazilian study done between November 2010 and April 2011 the data from 12,343 elderly patients, which showed a $33.3 \%$ prevalence of major potential drugdrug interactions [13]. Our results evidently display that the ratio of potential drug-drug interactions/number of prescriptions is directly proportional to the number of medications prescribed per patient, in agreement with the outcomes of preceding researches [14]. Most identified drug-drug interactions were recognized in prescriptions written by internal medicine specialist, orthopedics, general practitioners, ENT specialist, and general surgeon and these physicians commonly written a greater number of drugs per prescription than others.

In the current study, the most common major drug-drug interactions were between ciprofloxacin antibiotic with other medication such as using citalopram together with ciprofloxacin can increase the risk of an irregular heart rhythm that may be serious and potentially life threatening. Some specific medications were intensely related with clinical drug-drug interactions such as amitriptyline, which interacted with a must of the common cold and flu medications including acetaminophen, chlorpheniramine, dextromethorphan, and phenylephrine [15].

The results showed that there is a problem of drug-drug interactions in prescriptions dispensed in community pharmacies in Al-Najaf city and establish the necessity for the routine usage of an enhanced dependable computerized screening system for drug-drug interactions. At present, many Al-Najaf pharmacies are equipped with a computer program for dispensing the drug, and therefore adding a drug-drug interaction screening system to that software appears possible in the near future. Greater researches with more hospital or community may provide more results that are dependable [16]. The routine uses of computerized prescriptions by physicians, bar codes to help in the identification of patients and their drugs, the application of a perfect system providing new scientific substantiation, as well as good choice of drug, are some of the recommendations strongly suggested currently to physicians [17]. Moreover, clinical pharmacists have a vital function in recognizing and avoiding drug-drug interactions in prescriptions dispensed to patients [18].

To develop an investigation of drug-drug interactions, numerous computerize screening software which identifies about drug-drug interactions have been established and assessed [19]. Often there are incompatible data between the several medications interaction because the organization of the severity of drug-drug interactions is not all the time straight forward. Therefore, the application of computerize screening system capable of discovering drug-drug interactions 
at hospital and community pharmacies has not removed the need for clinical pharmacists to have a hard understanding of drug-drug interactions.

\section{CONCLUSIONS}

The result of this study is that prescriptions dispensed in community pharmacies in Al-Najaf city shown a great incidence of drug-drug interactions in prescribed drugs. In particular, patients on multiple medications for respiratory disease and coronary diseases and patients receiving antidepressant, antibiotics, and common cold medications should be carefully observed for adverse results from drug-drug interactions. Recognizing and avoiding dangerous major drug-drug interaction is a critical factor of a clinical pharmacist's job, and the role of the pharmacist should be moved from medication-oriented to patient-oriented. Physician's especially internal medicine specialist, orthopedics, general practitioners, ENT specialist, general surgeon, and pharmacists must stay alert in their checking of drug-drug interactions and create suitable prescription modifications. The application of a computerize screening system to identified drug-drug interaction, which would provide pharmacists with the correct data to evaluate the degree of hazard to the patient and to avoid an adverse effect due to exposure to the interacting medications.

\section{ACKNOWLEDGMENT}

The researchers be interested to be grateful thanks to the pharmacists of the community pharmacies for their support during the study.

\section{REFERENCES}

1. Bond CA, Raehl CL. Adverse drug reactions in United States hospitals. Pharmacotherapy 2006;26:601-8

2. Merlo J, Liedholm H, Lindblad U, Björck-Linné A, Fält J, Lindberg $\mathrm{G}$, et al. Prescriptions with potential drug interactions dispensed at Swedish pharmacies in January 1999: Cross sectional study. BMJ 2001;323:427-8.

3. Bjerrum L, Andersen M, Petersen G, Kragstrup J. Exposure to potential drug interactions in primary health care. Scand J Prim Health Care 2003;21:153-8.

4. Yanti E, Kristin E, Yasmina A. Potential drug interactions in hypertensive patients in Liwa district hospital, Lampung Barat, Indonesia. Int $\mathbf{J}$ Pharm Pharm Sci 2017;9:134-8.

5. Becker ML, Caspers PW, Kallewaard M, Bruinink RJ, Kylstra NB, Heisterkamp S, et al. Determinants of potential drug-drug interaction associated dispensing in community pharmacies in the Netherlands. Pharm World Sci 2007;29:51-7.

6. Tamargo J, Le Heuzey JY, Mabo P. Narrow therapeutic index drugs: A clinical pharmacological consideration to flecainide. Eur J Clin Pharmacol 2015;71:549-67.

7. Kumar L. Pharmacovigilance/reporting adverse drug reactions: An approach to enhance health surveillance and extending market share by minimizing the chances of drug withdrawals. Int J Pharm Pharm Sci 2015;7:1-7.

8. Glassman PA, Simon B, Belperio P, Lanto A. Improving recognition of drug interactions: Benefits and barriers to using automated drug alerts. Med Care 2002;40:1161-71.

9. Chrischilles EA, Fulda TR, Byrns PJ, Winckler SC, Rupp MT, Chui MA, et al. The role of pharmacy computer systems in preventing medication errors. J Am Pharm Assoc (Wash) 2002;42:439-48.

10. Drug Interactions Checker. Denver CO: Cerner Multum Inc. Available from: https://www.drugs.com/drug interactions.html.

11. Chatsisvili A, Sapounidis I, Pavlidou G, Zoumpouridou E, Karakousis VA, Spanakis M, et al. Potential drug-drug interactions in prescriptions dispensed in community pharmacies in Greece. Pharm World Sci 2010;32:187-93

12. Sepehri G, Khazaelli P, Dahooie FA, Sepehri E, Dehghani MR. Prevalence of potential drug interactions in an Iranian general hospital. Indian J Pharm Sci 2012;74:75-9

13. Obreli Neto PR, Nobili A, Marusic S, Pilger D, Guidoni CM, Baldoni Ade O, et al. Prevalence and predictors of potential drug-drug interactions in the elderly: A cross-sectional study in the Brazilian primary public health system. J Pharm Pharm Sci 2012;15:344-54.

14. Janchawee B, Wongpoowarak W, Owatranporn T, Chongsuvivatwong V. Pharmacoepidemiologic study of potential drug interactions in outpatients of a university hospital in Thailand. J Clin Pharm Ther 2005;30:13-20.

15. Hellbom E. Chlorpheniramine, selective serotonin-reuptake inhibitors (SSRIs) and over-the-counter (OTC) treatment. Med Hypotheses 2006;66:689-90.

16. Astrand B, Montelius E, Petersson G, Ekedahl A. Assessment of eprescription quality, an observational study at three mail-order pharmacies. BMC Med Inform Decis Mak 2009;9:8.

17. Heikkilä T, Lekander T, Raunio H. Use of an online surveillance system for screening drug interactions in prescriptions in community pharmacies. Eur J Clin Pharmacol 2006;62:661-5.

18. Tamblyn R, Huang A, Perreault R, Jacques A, Roy D, Hanley J. The medical office of the $21^{\text {st }}$ century (MOXXI): Effectiveness of computerized decision-making support. Pharm World Sci 2010; 32:187-93.

19. Vonbach P, Dubied A, Krähenbühl S, Beer JH. Evaluation of frequently used drug interaction screening programs. Pharm World Sci 2008;30:367-74 